\title{
Spatial Analysis of Noise in Kufa University (Kufa River Campus) using GIS
}

\author{
Raghad N. Hussein ${ }^{1}$, Ahmed H. Al-Sulttani ${ }^{2 *}$ \\ ${ }^{I}$ Map Production Department, State Commission of Survey, Ministry of Water Resources, Baghdad, Iraq, \\ raghadnassier13@gmail.com \\ ${ }^{2}$ Environmental Planning Department, Faculty of Physical Planning, University of Kufa, Najaf, Iraq, \\ ahmedh.alsulttani@uokufa.edu.iq \\ *Correspondence: ahmedh.alsulttani@uokufa.edu.iq
}

\begin{abstract}
Noise refers to unwanted sound, which causes great discomfort to the ears, and is usually measured in decibels. Very high levels of sound above $100 \mathrm{~dB}$ cause permanent hearing loss. This study deals with effect of noise in the academic areas, University of Kufa, Kufa river campus (Faculty of Urban Planning, Faculty of Law, Faculty of Archeology). Kufa river campus area is exposed to several external noise types. Noise field data have been measured and collected for 98 station points. The noise intensity ratio was measured using the Sound Level Meter at three different times during the working hours in the morning hours (8.30-10.30), at noon (10.30-12.30), and in the afternoon from (12.30-2.30). The data were analyzed using the Excel program (percentile method) to obtain a noise level values at $10 \%, 50 \%$, and $90 \%$ of data after arranging it ascendingly. The equivalent noise level (Leq) is calculate as well. The equivalent noise level data converts to GIS program form mapping and studying the spatial variation of noise intensity using a Spline interpolation method. The results showed that the effect of external noise is much greater than the effect of internal noise. The highest noise intensity at the points near the fence reached 94 decibels, and the lowest noise ratio was in the center of the faculty of Physical Planning, and the points near the green trees reached $45.1 \mathrm{db}$.
\end{abstract}

Keywords: Noise, Academic campus, Spatial, Spline, GIS, Kufa

Received: November $4^{\text {th }}, 2020$ / Accepted: December $26^{\text {th }}, 2020$ / Online: January $2^{\text {nd }}, 2021$

\section{Introduction}

The (noise) refers to an unwanted sound that causes great noise in the ears and is usually measured in decibels. Noise is a big problem when sound levels exceeding 100 decibels, which can cause permanent hearing loss. The study of noise pollution has received great attention because of its harmful effects on public health. Therefore, the causes of noise must be examined to improve human health (Berglund, Lindvall, Schwela, \& Organization, 1999; Niskar et al., 2001). In educational facilities, noise is a real problem and directly impacts the quality of education. Ideally, the sound level should be about $35 \mathrm{db}$ in classrooms (Akintunde, Bayei, \& Akintunde, 2020; Goswami, Hassan, \& Sarma, 2018).

According to the laboratory, field, and epidemiological studies, it was found that there is a relationship between health effects such as heart disease and others and long exposure to certain noise levels (Basner et al., 2014; Berglund et al., 1999; Verbeek, Van Dijk, \& De Vries, 1987). There is a close relationship between poor mental performance, level of education, and noise level, especially in studies that require thinking and mental effort. The people's mental ability is affected a lot by exposure to noise for one second reduces focus for 30 seconds (Berglund et al., 1999). 
Many studies have been implemented to study the impact of noise pollution in educational areas. Ozer et al. (2014) measured the noise in Ataturk University's campus in Erzurum, Turkey. The study results revealed that the noise level was more than $55 \mathrm{~dB}$, ranging between (62-70) dB. Maps were created to indicate the noise levels throughout the campus, to be used later as a reference in planning stages for new universities (Ozer, Zengin, \& Yilmaz, 2014). Padhy and Padhi (2008) explained that noise is a prominent feature in the environment. It has several types, including the noise generated by transport, industry, and individuals, and showed that the accurate measurement of noise levels is an essential part of the noise assessment. From June to December of 2005, the results showed that noise is widespread in the region, and the sources of noise are varied, including natural and traffic. The building's structural design plays a vital role in noise management (Padhy \& Padhi, 2008).

The study of noise in the University of Gauhati in India near the highway showed that the effect of traffic noise on the university was studied and measuring noise were taken in three time periods per day as the morning period extended from (9:00 to 11:00) and the midday period (12 hours to 11 hours). 2) The evening period (from 6 hours to 8 hours) in April and May. The noise level exceeded the permissible limits specified by the "Center for Noise Control in India" in the morning period, and the lowest noise level was in the midDaytime. (Phukan \& Kalita, 2013)

This paper is studying the spatial and temporal variation of noise on the educational campus at the University of Kufa, (Kufa river campus), which includes (faculty of Physical Planning, Faculty of Law, Faculty of Archaeology) using field-collected data and GIS.

\section{Study area}

The study area (Figures $1 \& 2$ ) is located in the Najaf Governorate district of Kufa, which has an area $\left(26,172.8 \mathrm{~m}^{2}\right)$. It extends between lat. $32^{\circ} 2^{\prime} 6^{\prime \prime}-32^{\circ} 2^{\prime} 10^{\prime \prime} \mathrm{N}$ and long. $44^{\circ} 24^{\prime} 32^{\prime \prime}, 44^{\circ} 24^{\prime} 40^{\prime \prime} \mathrm{E}$, to the east of An-Najaf governorate along with Euphrates river (Kufa part).

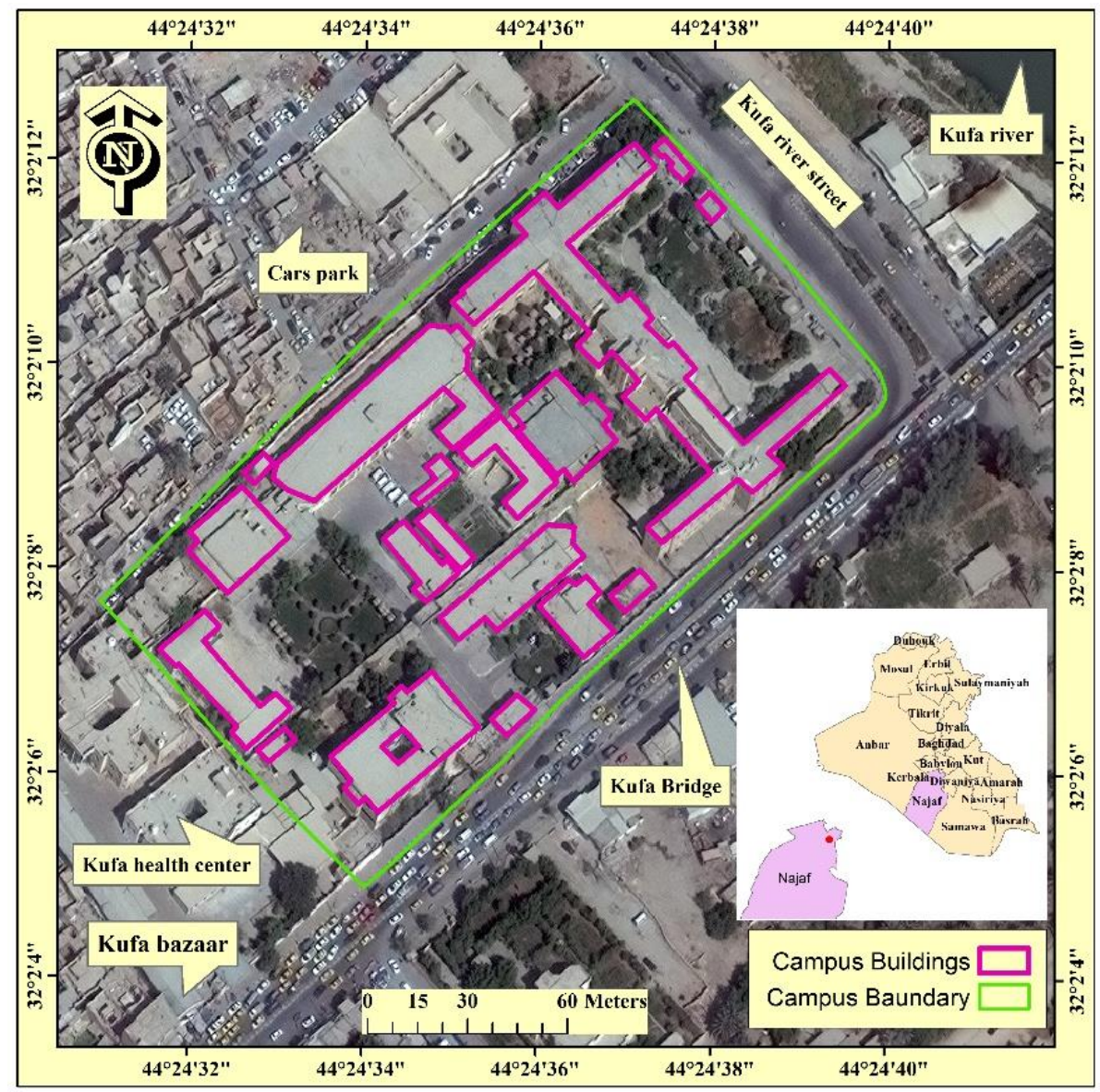

Figure 1. Study area 


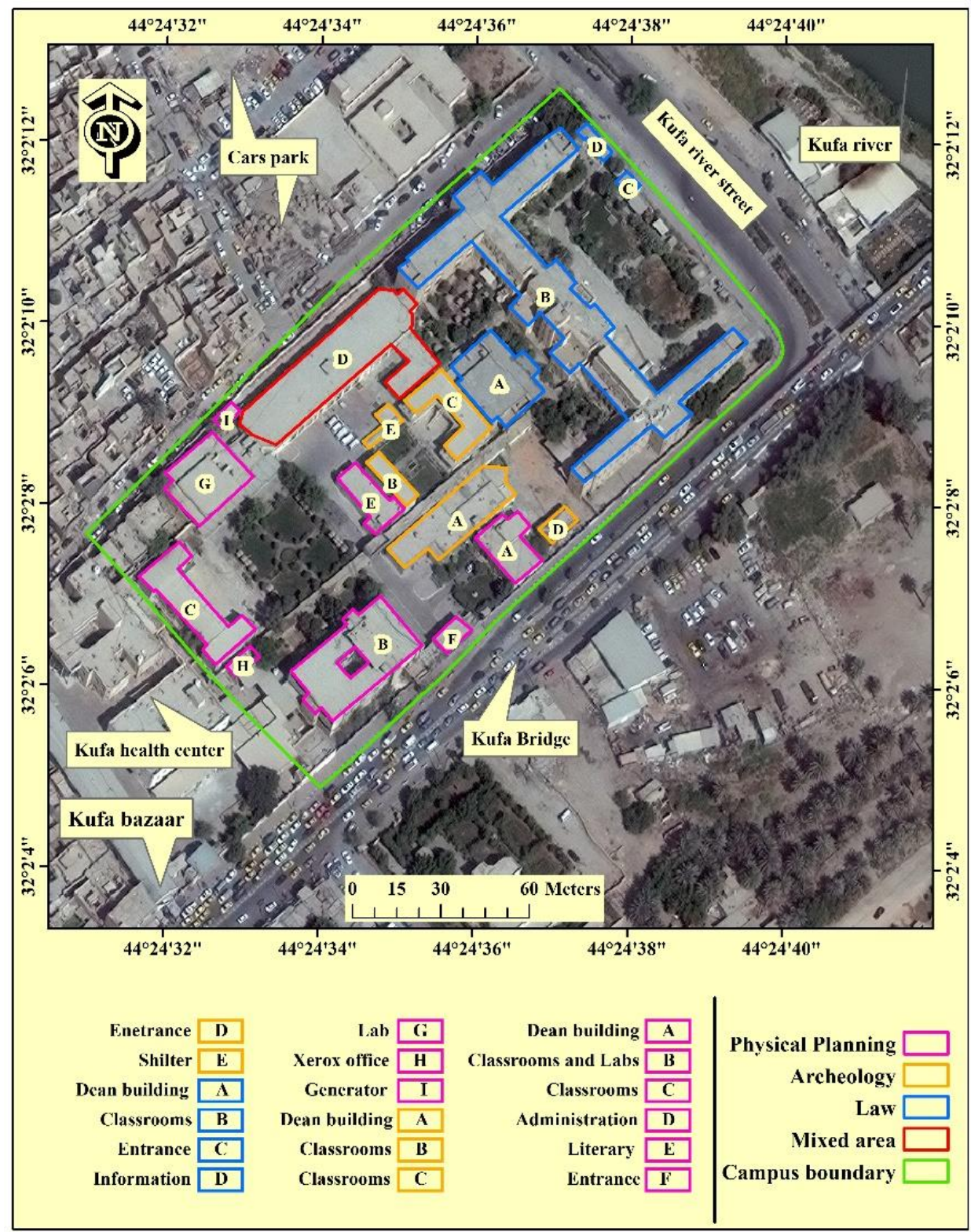

Figure 2. The University of Kufa Campus buildings

\section{Material and Method}

\subsection{Material}

The recording of noise levels has been done and covered the whole study area with enough station points (98 points) to study the variation of intensity of noise and interpretation the results to discuss the spatial variation. Sixty station points are inside the campus with distance (from 8 to $20 \mathrm{~m}$ ), and 38 points outside the campus (Figure 3).

Noise detector type (B07FLX8L49) has been used to measure the noise in each station point. The recording of noise levels for each point was for an average time equal to 30 minutes every three times (morning from 8:30 to 9:30, noon from 10:30 to 11:30, afternoon from 1:30 to 2:30) by using two devices for measured intense of noise called (sound level meter) for 50 days. All collected data have been processed using MS Excel software. 


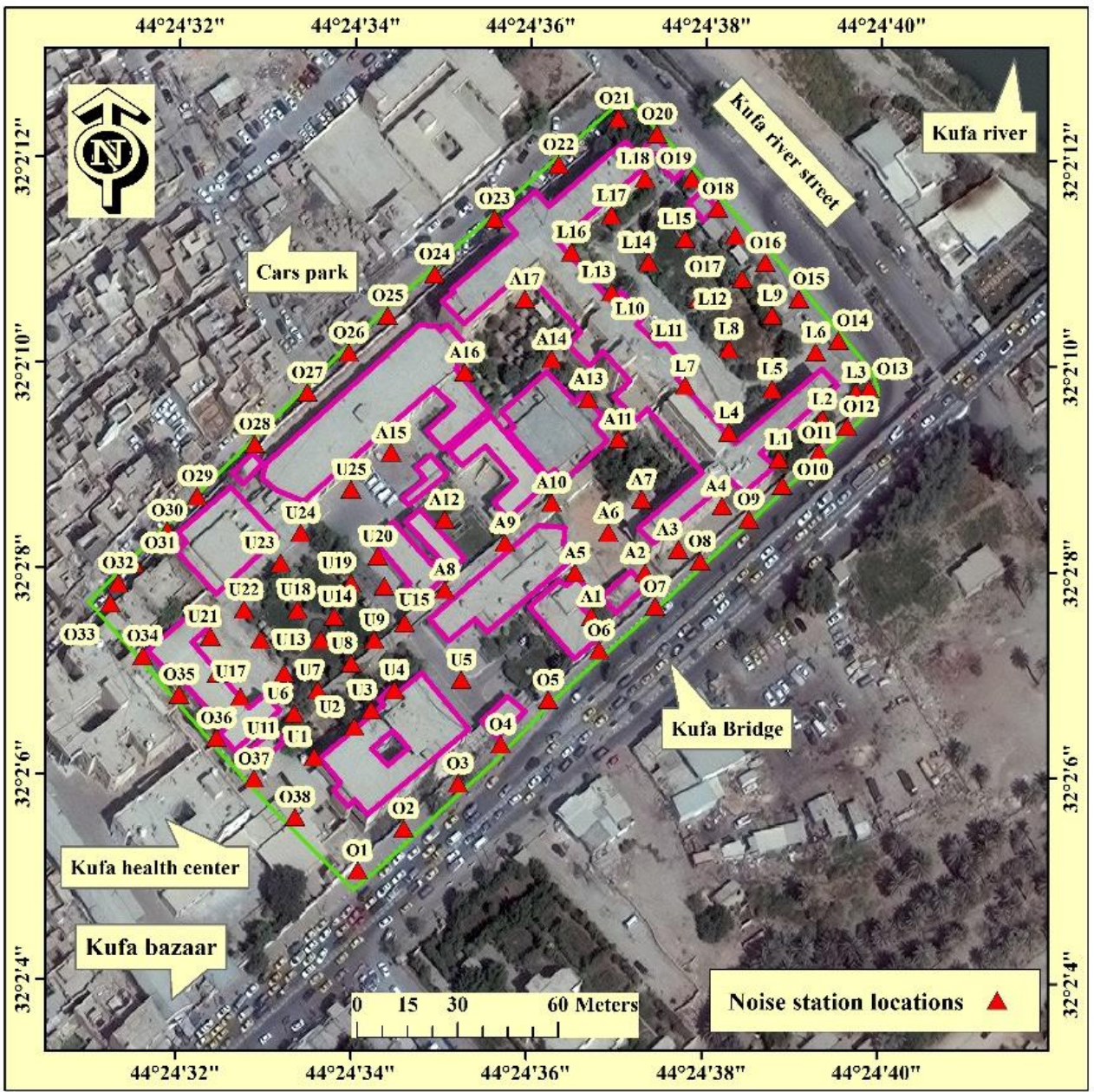

Figure 3. Noise measurement station points.

\subsection{Method}

Equivalent noise level (Leq) has been calculated for each point every time. Equivalent noise level is defined as a constant sound level with the same level of acoustic energy as an oscillating level over a specified time. The equivalent continuous noise level has been adopted in many countries to measure and evaluate noise. It is called by several names, including the energy level and the continuous sound level. It is expressed mathematically using the following equation (Avinash, 2010).

Leq $=\mathrm{L}_{50}+\left(\mathrm{L}_{10}-\mathrm{L}_{90}\right)^{2} \backslash 56 \mathrm{db}$

Leq $=$ equivalent noise level

$\mathrm{L} 10=$ Noise level that exceeds $10 \%$ from readings

L50 $=$ Noise level that exceeds $50 \%$ from readings

L90 $=$ Noise level that exceeds $90 \%$ from readings

3- Interpolation:

The second step of work is processing data to create spatial maps using interpolation tools in geographic information systems (GIS). There are many techniques for interpolation to study the variation in the intensity of noise in the study area. The spline method shows the best results in the variation of intensity of noise.

Spline estimates grid cell values by fitting a minimum-curvature surface to the sample data. It is like a flexible sheet of plastic that passes through each data point but bends as little as possible. The difference between regularized and tension splines is flexibility. 


\section{Results}

The result illustrates the computation of equivalent noise level in three different times (morning from 8:30 to $10: 30$, noon from 10:30 to $12: 30$, afternoon from 12:30 to 2:30). In the morning, the computation of equivalent noise level shows that the intensity of noise level exceeded the limit of more than $70 \mathrm{db}$ at the faculty of Physical Planning, faculty of Law, and the street that led to the faculty of Law Figure. 4. The spatial analysis of noise distribution was along the road from the bridge to the entrance of the faculty of Law (traffic noise). Noise intensity is reduced in the area behind the campus. The road leads to the bazaar, and the back garden located between Archeology and Law, because these places are located far from traffic noise.

In the noon, the spatial distribution of equivalent noise level is exceeded $75 \mathrm{db}$ in the classrooms building corridor in faculty of Physical Planning Figure. 5. Through the maps resulting from analyzing the data taken at (students' resting time between lectures). It was noticed that the highest noise values were recorded at the entrance to the classroom buildings, especially at the faculty of Physical and Law. Speaking loudly and using mobile phones at times increase the noise intensity in addition to the outside noise

In the afternoon, the noise level is reached to a maximum level of more than $90 \mathrm{db}$ and a minimum $60 \mathrm{db}$ that means there is a very high dangerous noise level (Figure 6). The highest value of the afternoon's noise level is near the study area's boundaries. This shows the effect of outside noise and the students crowding near the faculty gates near the library of the faculty of Physical Planning Archeology, and Law. The rising of noise intensity at those places is because of student and teacher cars and bus traffic noise.

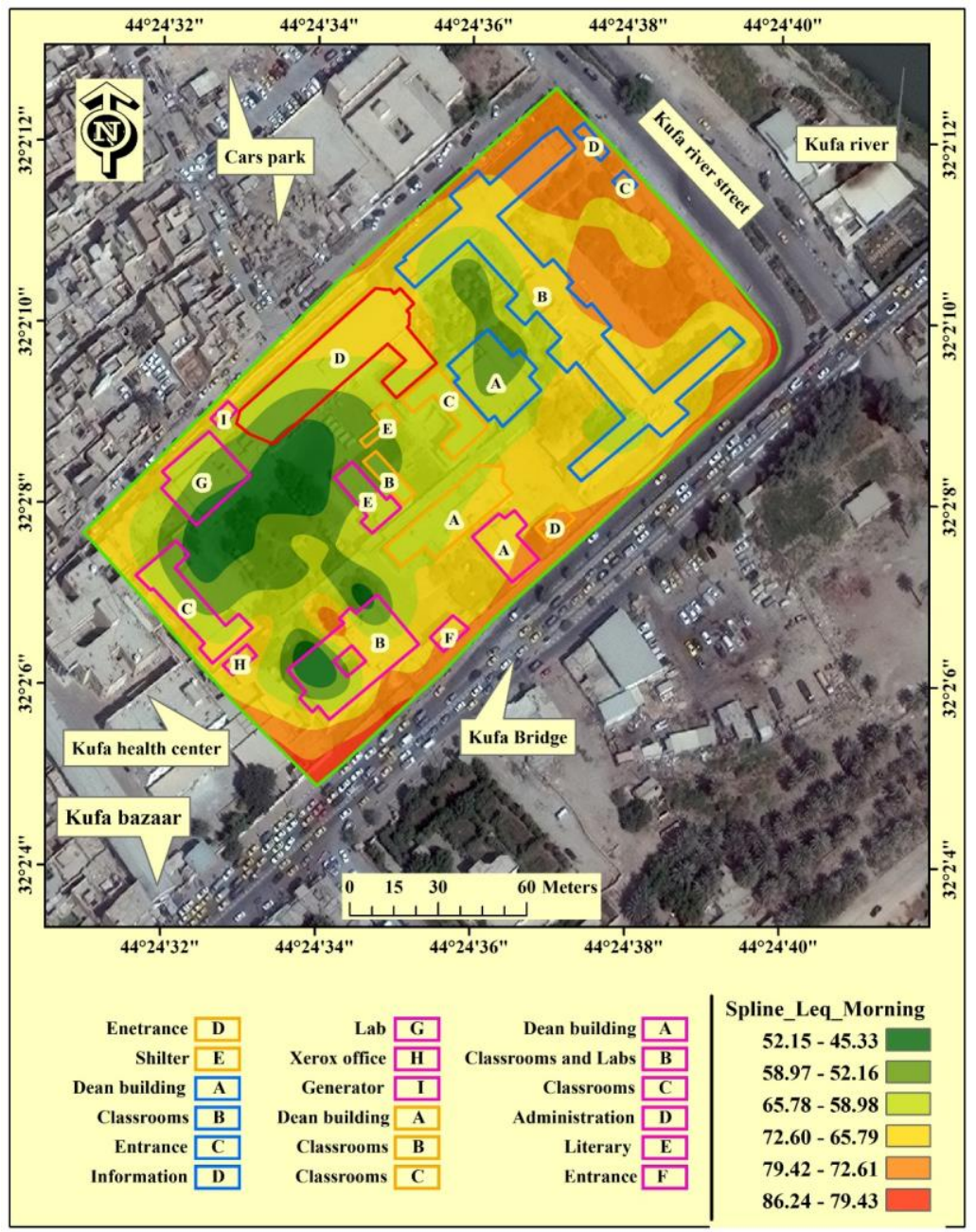

Figure 4. Interpolation Map of Equivalent Noise levels in the morning.

Traffic noise significantly affects the study area and is the first noise source in the area. The areas most affected by noise are the building of the classrooms at the faculty of Physical Planning and faculty of Law 
(that is, the areas near the outer fence). The least affected areas are the faculty of Archeology and the areas surrounding the gardens and the building located between the faculty of Archeology and the faculty of physical planning. The lowest level of noise $44 \mathrm{~dB}$ in the morning in the area near the building between the faculties of Physical Planning, Archelogy, as well as near the Center of Faculty of Physical Planning and Garden Faculty of Archeology, and the highest level of intensity noise exceeds $91 \mathrm{~dB}$ near the outer fence of the study area, especially on the Kufa bridge side.

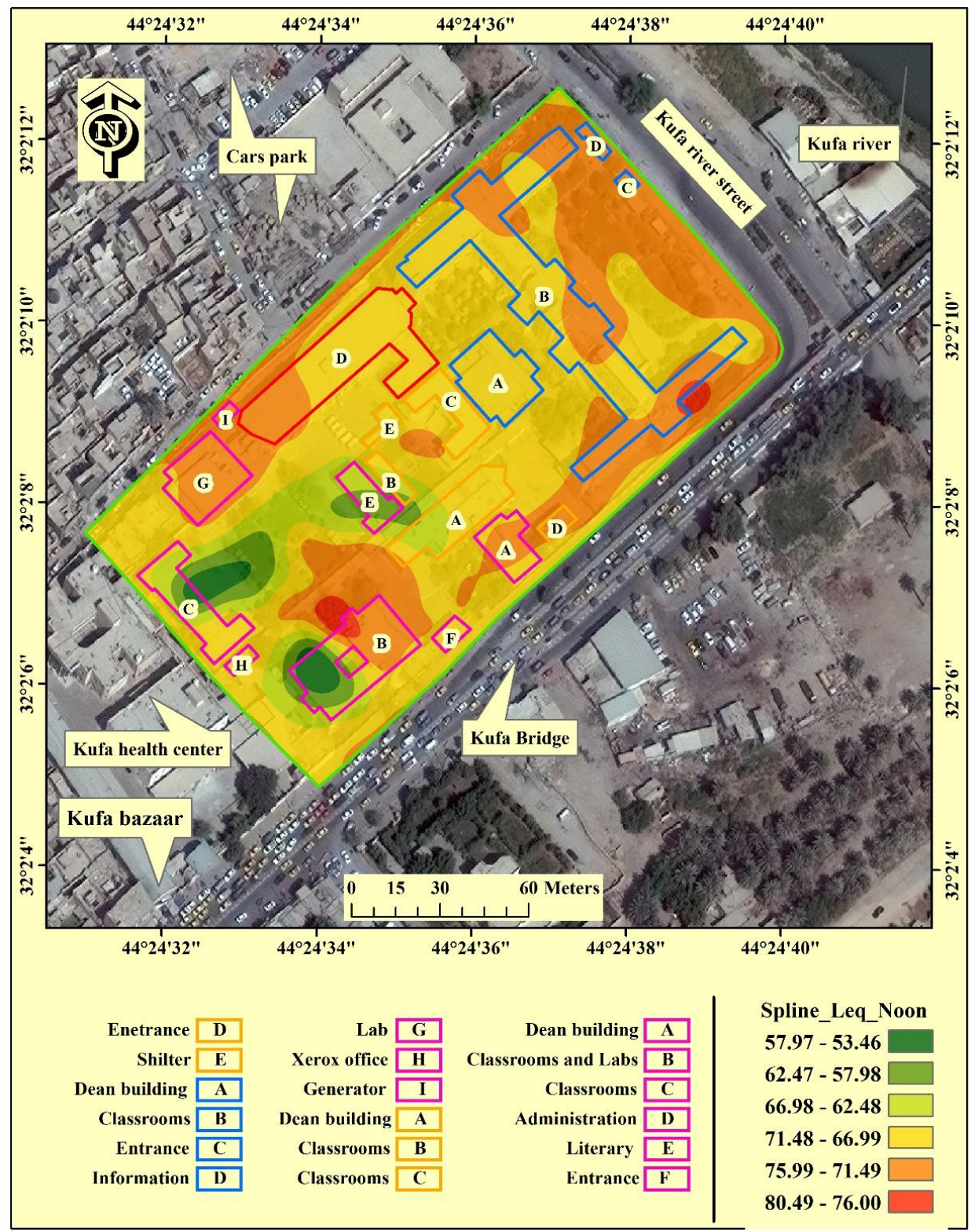

Figure 5. Interpolation Map of Equivalent Noise levels in the noon. 


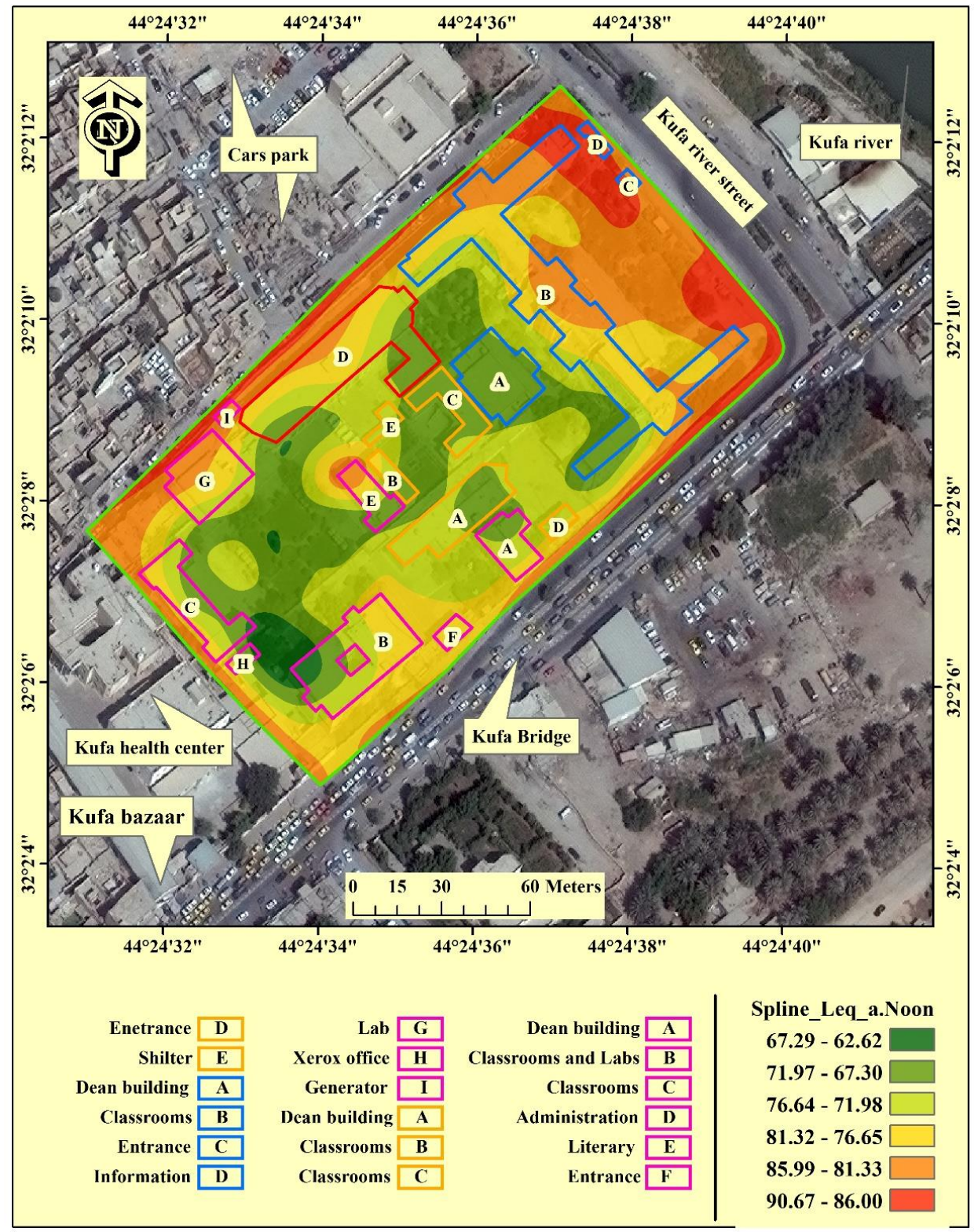

Figure 6. Interpolation Map of Equivalent Noise levels in the after noon.

\section{Conclusions}

After field data at three times and for 98 points distributed in the study area, and the statistical and GIS analysis, it found that the area is exposed to a very high noise level and does not match international standards, whether at the inside or outside. The spatial noise distribution maps using spatial interpolation show that the best type to represent the noise is Spline. It consists of polynomial sidelines connected to represent the surface between the measured readings and gives an ideal result closer to reality. It uses the least-squares method and the polynomial method.

Through fieldwork, the noise level is below when the whereabouts of green trees, especially in the garden of the Faculty of Physical Planning. It means that the density of the trees can reduce the noise that comes from outside the campus. Green belts surrounded the campus will reduce the noise significantly.

The design aspect of buildings can create a suitable environment for living, working, and studying using the correct design. Developing strategies and carefully selecting the building elements in the design phase, so noise control must get serious attention. In the study area, it is difficult for us to rebuild buildings from many aspects, including cost, procedures, and difficulty in obtaining legal approval for reconstruction. Therefore, we will resort to other methods to reduce noise, including: 
- Renovate the exterior of buildings, use sound-insulating materials, sound-absorbing materials, and make the facade rough to weaken the reflected sound waves.

- Reduce the windows in each of the classrooms, or making them double-glazed and repairing the damaged ones to make them airtight.

- The use of curtains with a thick cloth helps reduce the intensity of noise, and it is also possible to add somewhat thick floor coverings and cover the corridors with them to absorb the sound of those passing by in the corridor beside the classrooms.

\section{References}

Akintunde, E. A., Bayei, J. Y., \& Akintunde, J. A. (2020). Noise level mapping in University of Jos, Nigeria. GeoJournal, 1-13. Avinash, C. (2010). Assessment of noise level in different zones of Haridwar City Uttarakhand. In: Researcher.

Basner, M., Babisch, W., Davis, A., Brink, M., Clark, C., Janssen, S., \& Stansfeld, S. (2014). Auditory and non-auditory effects of noise on health. The lancet, 383(9925), 1325-1332.

Berglund, B., Lindvall, T., Schwela, D. H., \& Organization, W. H. (1999). Guidelines for community noise.

Goswami, B., Hassan, Y., \& Sarma, A. J. (2018). The effects of noise on students at school: A review. International journal of latest engineering and management research (IJLEMR), 3(1), 43-45.

Niskar, A. S., Kieszak, S. M., Holmes, A. E., Esteban, E., Rubin, C., \& Brody, D. J. (2001). Estimated prevalence of noiseinduced hearing threshold shifts among children 6 to 19 years of age: the Third National Health and Nutrition Examination Survey, 1988-1994, United States. Pediatrics, 108(1), 40-43.

Ozer, S., Zengin, M., \& Yilmaz, H. (2014). Determination of the noise pollution on university (education) campuses: a case study of Ataturk University. Ekoloji, 23(90), 49-54.

Padhy, P. K., \& Padhi, B. K. (2008). Assessment of noise quality in BolpurSantiniketan areas (India). J. Environ. Res. Develop, $3(1), 123-126$.

Phukan, B., \& Kalita, K. (2013). An experimental study of noise pollution in Gauhati University campus, Guwahati, Assam, India. International Journal of Environmental Sciences, 3(5), 1776-1784.

Verbeek, J., Van Dijk, F., \& De Vries, F. (1987). Non-auditory effects of noise in industry. International archives of occupational and environmental health, 59(1), 51-54. 